\title{
A Perspective on Cocaine Induced Stroke - Its Mechanisms and Management
}

\author{
HS Gendeh ', AR Chaudhary ${ }^{2}, \mathbf{S}$ Kamath ${ }^{3}$, A Shetty ${ }^{4}$, Z Javed ${ }^{5}$, S Munshi ${ }^{*} 6$ \\ ${ }^{1}$ Consultant Physician, Nottingham University Hospitals NHS Trust, Nottingham, UK \\ ${ }^{2}$ Registrar, Dept of Stroke, Nottingham University Hospitals NHS Trust, Nottingham, United Kingdom \\ ${ }^{3}$ Consultant Physician, Northern Lincolnshire and Goole NHS Foundation Trust, Grimsby, United Kingdom. \\ ${ }^{4}$ Consultant Physician, Dept of Stroke, Nottingham University Hospitals NHS Trust, Nottingham, United Kingdom \\ ${ }^{5}$ Resident Physician, Nottingham University Hospitals NHS Trust, Nottingham, United Kingdom \\ ${ }^{6}$ Consultant Physician, Nottingham University Hospitals NHS Trust, Nottingham, United Kingdom \\ *Corresponding Author: S Munshi, Consultant Physician, Nottingham University Hospitals NHS Trust, Nottingham, UK. \\ E-mail: sunil.munshi@nuh.nhs.uk \\ Received date: September 20, 2019; Accepted date: October 15, 2019; Published date: October 16,2019 \\ Citation: HS Gendeh, AR Chaudhary, S Kamath, A Shetty, Z Javed, S Munshi. (2019) A Perspective on Cocaine Induced Stroke - Its Mechanisms and \\ Management. J. Neuroscience and Neurological Surgery. 5(1); Doi: 10.31579/2578-8868 /094
}

Copyright: (C) 2019 S Munshi. This is an open-access article distributed under the terms of The Creative Commons Attribution License, which permits unrestricted use, distribution, and reproduction in any medium, provided the original author and source are credited.

\author{
Abstract \\ Cocaine misuse has been in the news recently with the Department of Health in the UK, recognising the seriousness of its \\ epidemic \\ Keywords: cerebrovascular disease; drugs; intoxication; ischaemia; haemorrhage; cocaine; management
}

\section{Interaction}

Cocaine misuse has been in the news recently with the Department of Health in the UK, recognising the seriousness of its epidemic. It is the most recurrent agent in drug-related strokes. [1,2] It has been linked to a poorer prognosis, with increased mortality and morbidity in young patients in comparison to other age-matched, drug-free stroke victims. [1,3]The emergence of cocaine abuse as a major risk factor for stroke in young patients 2 is linked to its consumption reaching worldwide epidemic proportions in the last two decades. In our own practice we have recognised it increasingly as a causative factor in young stroke patients. Its role in provoking stroke should be the subject of greater public awareness. Patients and health care professionals should be educated about the hazards and complications of cocaine use. This perspective contemplates the cerebrovascular effects of cocaine and their management.

Some facts and figures : The United States of America is reported to have 1.9 million current cocaine users in 2008 with adults aged 18 to 25 being the most prominent age group [4]. Recent data from the United Kingdom reported that approximately $2.2 \%$ (or 0.7 million) aged between 16 to 59 abused cocaine in the year 2011 and 2012 rendering it the second most commonly used drug after cannabis [5]. In Australia the 20- 29 year age group is the highest abuser of the drug [6]. There are a growing number of cocaine users in Asian countries such as India, Malaysia and Singapore; however detection is difficult as many abusers in these regions are from the higher socio-economic class [7].

Some historical facts: The natural alkaloid is extracted from the leaves of an Andean shrub, Erythroxylon coca or E. novgranatense. The leaves were chewed by indigenous populations of north-western South America to counter fatigue and hunger and also used to prepare a tea to treat mountain sickness. [8]

In Europe the first appearance of cocaine was in the form of extracts from the coca leaf. Vin Mariani, a coca wine was produced in France before 1870 and advocated for lassitude, melancholy and as a general tonic for the body and the mind. Another The coca drink, coca cola, contained $2.5 \mathrm{mg}$ of cocaine per $100 \mathrm{ml}$ in 1900, the last year of its presence in this product. Cocaine extracts were also available as pastilles, elixirs and chocolate bars prepared by pharmacists [9].

In 1880's it was reported as a cure for alcoholism and morphine addiction. The general enthusiasm for cocaine and its actual euphoriant properties together with the absence of a legal frame regulating its marketing in the United States paved the way for the first cocaine epidemic in 1910. In the UK, cocaine fell under the Pharmacy Act of 1868, which limited its availability to pharmacists and physicicians [9].

After an almost complete eradication of the cocaine epidemic by the 1930s, the drug started to reappear in the US in the 1960s and reached epidemic proportions in the 1980 s with the appearance of cocaine free base or "crack".

Pharmacokinetics: Cocaine is absorbable from all body mucous membranes. [10] It is metabolised into inactive water-soluble ecgonine methyl ester by liver esterases and serum pseudocholineseterase. Spontaneous non-enzymatic plasmatic hydrolysis leads to the formation of benzoylecgonine, then ecgonine. These hydrolytic processes account for $80-90 \%$ of urinary cocaine metabolites. 11 Its metabolites remain detectable in blood or urine for 24 to 36 hours after ingestion.[12,13]

Cocaine and its metabolites can also be detected in human hair, using gas chromatography and mass spectrography. Hair analysis tests are described as highly sensitive and specific in detecting cocaine use even after disappearance of urinary metabolites. [14]

Mechanism of action: Cocaine has local anaesthetic properties and when given systemically, acts as a powerful sympathomimetic agent by blocking the presynaptic reuptake of norepinephrine (NE) and dopamine. [10,13] The rise in synaptic NE was traditionally held responsible for the sharp rise in blood pressure following cocaine use, [13]. We now have a better understanding of this mechanism. The baroreceptor reflexes in healthy individuals indirectly regulate the degree of peripheral vasoconstriction by determining the level of central sympathetic outflow. Excessive adrenergic vasoconstriction is due to an inhibition of peripheral NE reuptake coupled with an unrestrained central sympathetic outflow due to absent altered baroreceptor reflexes. It has been speculated that the blood pressure-raising 
effect of cocaine is excessive in patients with long-standing hypertension, heart failure or other conditions due to impaired baroreceptor reflexes [15].

The anti-muscarinic properties of cocaine on myocytes, explains the suppression of vagal reflexes that should accompany the sympathomimetic effect of cocaine. This also explains why the cocaine-related rise in blood pressure is accompanied by tachycardia instead of a compensatory bradycardia. [16]

Moreover, repeated episodes of vasoconstriction and subsequent ischaemia due to frequent cocaine snorting may cause nasal septal perforation. Our team has previously described several cases with septal perforation due to intranasal cocaine abuse [17] . Similarly, several cases of cocaine induced ischaemic myelopathy and spinal cord infarction have been reported.

Cocaine as a risk factor for stroke: Drug abuse is one of the most common conditions predisposing to stroke in young adults; $[2,18]$ The first report of a stroke associated with cocaine abuse was published in 1977 [19]. The risk for stroke is significantly high during the first 6 hours after drug abuse, with a

relative risk of $46.5 \%$. The risk subsequently decreases with time. In one study cocaine was the most frequently used drug (57\%) [2]. In one sample study, the sex ratio for cocaine-related strokes was 20:7 (male to female) and the mean age was $38(+/-8.5 \mathrm{SD})$ years [3]. However, cocaine-related stroke might be more prevalent in people of a higher age, than traditionally taught [20].

Pathophysiology of cocaine-related stroke: Cocaine has been linked to both ischaemic and haemorrhagic strokes. Alkaloidal cocaine has been associated to both types of stroke in equal proportions, whereas cocaine hydrochloride was associated with haemorrhagic stroke in approximately $80 \%$ of cases [18]. Overall cerebral haemorrhages are more frequent than cerebral infarctions independent of the type of cocaine or its route of administration [21]. Various mechanisms are outlined in Table 1.

\begin{tabular}{|c|c|c|}
\hline \multicolumn{2}{|l|}{ General } & \multirow[t]{2}{*}{ Specific } \\
\hline Acute & Long term & \\
\hline $\begin{array}{l}\text { History } \\
\text { (Patient, Medical records, } \\
\text { collateral history) }\end{array}$ & $\begin{array}{l}\text { Rehabilitation } \\
\text { (Physiotherapist, Speech \& } \\
\text { language, Occupational } \\
\text { therapist, Psychologist) }\end{array}$ & $\begin{array}{l}\text { Diazepam, } \\
\text { Hypothermia, } \\
\text { Consideration of use } \\
\text { of intravenous }\end{array}$ \\
\hline $\begin{array}{l}\text { Imaging } \\
\text { (CT/ MRI Brain) } \\
\text { CT or MR angiogram, } \\
\text { Carotid ultrasonography }\end{array}$ & $\begin{array}{l}\text { Cardiovascular assessment } \\
\text { ECG, Echocardiogram }\end{array}$ & $\begin{array}{l}\text { magnesium, } \\
\text { corticosteroids, }\end{array}$ \\
\hline $\begin{array}{l}\text { Correct Hypertension } \\
\text { (IV Labetaolol, IV Glyeryl } \\
\text { trinitrate) }\end{array}$ & $\begin{array}{l}\text { Neurological assessment with } \\
\text { NIHSS ( National Institute of } \\
\text { Health Stroke Scale) }\end{array}$ & \\
\hline $\begin{array}{l}\text { Thrombolyse } \\
\text { (if ischaemic and no } \\
\text { contraindication; and within } \\
4.5 \text { hours of onset) }\end{array}$ & $\begin{array}{l}\text { Education / Counselling } \\
\text { Therapy for drug abuse }\end{array}$ & \\
\hline
\end{tabular}

Table 1: Summary of management of cocaine related stroke

Thrombosis, whether linked to vasospasm, was proposed as a mechanism of cocaine related stroke [18,22]. Cocaine can increase platelet aggregation via an enhanced response to arachidonic acid [23]. Three cases of cocaine-related stroke associated with positive anti-cardiolipin antibodies have been described in two reports [24,25].

Embolism is mentioned as a possible mechanism [26], either following endocarditis 2 or cocaine-induced cardiomyopathy [27]. Hypotension with cerebral ischaemia [28] following myocardial infarction [29] or ventricular fibrillation [30] caused by cocaine consumption has been incriminated.

There are some reports of cerebral vasculitis associated with cocaine abuse $[21,31,34]$. Both angiography and brain biopsy were used to demonstrate vasculitis, although angiography does not seem to be very reliable [32]. Small vessels vasculitis has been described in very few cases of cocaine related strokes and it is difficult to separate its role in the event from that of cerebral vasospasm. The causes of cocaine associated vasculitis are not well understood but it has been associated with a progressive symptoms over weeks and an elevated Erythrocyte Sedimentation Rate (ESR) [31,33].

Cerebral vasospasm is thought one of the most likely mechanisms of cocainerelated ischaemic strokes [18,35]. A study utilised Magnetic Resonance Angiography (MRA) imaging to demonstrate that cocaine was actually responsible for the induction of cerebral vasoconstriction. This effect was dose-related. Repeated exposures result in a higher incidence of cerebral vasoconstriction [36]. Cerebral vasospasm has been suggested as an incriminating factor in cocaine-associated intra-cranial haemorrhage (ICH) with absent vascular pathology at autopsy [37].

Among designer drugs, cocaine is believed to be the one of the largest causes 
of ICH in young adults [1]. Bleeds were thought to be a consequence of an outburst in blood pressure following the ingestion of the drugs. However cocaine-related ICH is more likely to occur in patients with underlying cerebral vascular abnormalities $[1,22]$. It is suggested that cocaine predisposes to aneurysmal rupture in smaller aneurysms and at a younger age [38]. In a small study of 13 patients with drug-related ICH, seven were found to have intracranial aneurysms and 3 had arteriovenous malformations. Cerebral angiography should be part of the evaluation of most young patients with ICH"1. Moreover, cocaine induced ICH frequently results in intraventricular extensions [39].

Other contributing risk factors predisposing to stroke are platelet activation via CD40L (sCD40L), Neutrophil-Activating Peptide-2 (NAP-2) and 'regulated on activation, normal T cells expressed and secreted' (RANTES) resulting in higher intravascular thrombus formation and early onset atherosclerotic changes [40]. RANTES (CCL5 or Chemokine ligand 5) is a ligand expressed on many haematopoietic and non-hamematopoietic cell types and plays an important part in homing and migration of memory T-cells. Vascular changes include abnormalities of the infolding of the tunica interna and disruption of the tunica externa in ischaemic strokes. Several colleagues have reported the presence of inflammatory mononuclear cells cuffing in cortical and meningeal venules with transmural lympho-monocytic infiltration in a 21-year old stroke patient with cocaine abuse: suggesting vessel inflammation secondary to ischaemic changes with no definitive evidence of vasculitis. Table 1:

Mechanisms of ischaemic stroke in Cocaine users:

Vasospasm - Disorder of Calcium-Magnesium homeostasis Sympathomimetic effect of cocaine

Platelet activation

Apoptosis of cerebral vascular smooth muscle cells

Cardio-embolism ( endocarditis, arrhythmia, cardio-myopathy)

Disorder of cerebral auto-regulation

PRES ( Posterior reversible encephalopathy syndrome)

RCVS ( Reversible cerebral vasoconstriction syndrome)

Vasculitis

Premature atherosclerosis

Dysfunction of vascular endothelial cells

Management: All physicians need to be aware of the need to recognise and treat cocaine induced stroke. We categorise this into the general management of an ischaemic or haemorrhagic stroke and additional management in cocaine abusers (Table 2).

The general management of stroke can be further subcategorised into an acute/hyper-acute phase and long term management of stroke for the purposes of simplicity. Obtaining a history of drug abuse in an acute stroke patient is challenging, especially if the patient presents with confusion or dysphasia, or if no collateral history is available. Therefore, a quick glance of previous medical records and a collateral history from family or healthcare/social assistants is often helpful. As a general rule of thumb, the gold standard management of an acute stroke/suspected stroke either in a stroke or nonstroke specialist centre among patient should include an urgent head imaging (either a computed tomography, CT head or MR imaging/MRI) to rule out a haemorrhagic stroke. If a bleed is seen, a neurosurgical opinion should be sought urgently.

In an absence of a bleed, we thrombolyse patients within 4.5 hours (as supported by ECASS-3trial [41] and the IST-3 trial [42]) from a definite time of onset. A small scale study on the use of intravenous tissue plasminogen activator (tPA) showed similar safety outcomes on twenty nine $(n=29)$ cocaine positive strokes as compared to seventy five $(n=75)$ cocaine negative strokes [43]. However, cocaine-induced hypertension should be identified and corrected prior to thrombolysis. In most cases, patients with severe uncontrolled hypertension or Systolic Blood Pressure (SBP) >185, we prefer to correct any severe hypertension via the administration of intravenous antihypertensives prior to thrombolysis. Intravenous Labetalol is the drug of choice in our centre and throughout the UK. In addition, cocaine-induced agitation can be managed with intravenous diazepam and hypothermia should be corrected to maximise reperfusion in an ischaemic setting.

The long term management of a stroke involves rehabilitation provided by a multidisciplinary team(MDT) of physicians, physiotherapists, speech and language therapists, occupational therapists and psychologists with set and optimistic recovery plans with goal-setting. However, not all regions in Asia have the facilities of an MDT or of the diversity of care professionals and a lot will depend on the healthcare setting of the given region. Studies have shown that stroke patients have a more favourable recovery in a stroke centre/ institute with the provision of a specific stroke related care [44]. A full cardiovascular and neurological workout should include an electrocardiogram (ECG) and Echocardiogram (ECHO), carotid doppler for ischaemic stroke involving the anterior and middle cerebral arteries and an MR Angiogram for better visualisation of the cerebral blood vessels if deemed necessary. Cocaine induced stroke patients tend to have poorer functional recovery and prognosis as compared to the non-cocaine group [39].

Recent evidence suggests that cocaine induced vasospasm related ischaemia, detected early via the use of CT Angiogram/Perfusion allows its differentiation from thromboembolic induced ischaemia, therefore allowing for a more specific management [45]. In animal experiments, the administration of intravenous magnesium has an inhibitory effect on vascular spasms secondary to cocaine [46]. However, a randomised controlled trial by Muir et al in 2004 showed no significant improvement in mortality or morbidity after 90 days of an acute onset of stroke. [47] Corticosteroids and immunosuppressive drugs have been used for cocaine induced vasculitis; however there is still a need for more clinical data about its efficacy.

A large number of cocaine abusers do also suffer from a plethora of comorbidities i.e. hypertension, ischaemic heart disease, diabetes and psychological issues; these should be managed by their healthcare physicians appropriately to reduce the risks of the recurrence of a repeated stroke. This highlights the need for effective education regarding the intracranial effects of cocaine abuse among healthcare professionals who will be the first point of contact among cocaine abusers presenting with a stroke. Moreover, healthcare providers are often in a better position to educate and advise these patients accordingly. The 'Advisory Council on the Misuse of Drugs report [48] and recommendations on Powder Cocaine' published by the Department of Health in the UK, advocated various measures to counter this menace by various measures, namely:

1.Reducing demand

2.Building recovery

3. Restricting supply

4.Research

5.Data collection

The UK government's current approach, which builds on the commitments made under the 2010 Drug Strategy, balances co-ordinated action to restrict the supply of cocaine, activity to reduce the demand and treatment which allows anyone to recover and free themselves from dependency and minimise harm.

\section{Conclusion}

There is a great need to highlight cocaine as an incriminatory factor in the modern era in susceptible individuals. Cocaine-induced stroke is common in young people and increasingly recognised in middle-aged individuals as well. Although much is known about cocaine-induced stroke and its pathophysiology, there is still a great need for further research. There is a great need for specific pharmacological interventions at a molecular level to counter the cerebrovascular and other effects of cocaine and reduce the risks of strokes among cocaine abusers. Inevitably, healthcare physicians should encourage abstinence from cocaine abuse to prevent the widespread sideeffects of this drug and recurrences of future intracranial events.

\section{Disclosures}

The authors have no conflict of interest(s) or financial interest(s) to declare.

\section{Funding and Acknowledgement}

The authors have not received any funding for the writing and publication of this manuscript. The authors would like to the Department of Stroke Medicine, Nottingham City Hospital for their experience in managing cocaine related stroke.

\section{Author Contributions}

HS Gendeh was involved in design, data analysis, drafting of article and critical revision of article. S Kamath was involved in data analysis, drafting of article and approval of article. SK Munshi and Abdul Rehman Chaudhary were involved in data analysis, drafting of article, critical revision and 
approval of article. All authors have access to manuscripts that support the publication.

\section{References:}

1) McEvoy AW, Kitchen ND, Thomas DG. (1998) Intracerebral haemorrhage caused by drug abuse. The Lancet. 351(9108):1029

2) Kaku DA, Lowenstein DH. (1990) Emergence of recreational drug abuse as a major risk factor in young adults. Annals of Internal Medicine. 113(11):821-27.

3) Nanda A, Vannemredy P Willis B, Kelley R. (2006) Stroke in the young: relationship of active cocaine use with stroke mechanism and outcome. Acta Neurochir Suppl. 96:91-96.

4) Cocaine: Abuse and Addiction. NIH: National Institute on Drug Abuse. :

5) Extent and trends in illicit drug use among adults aged 16 to 59. Drug Misuse Declared: Findings from the 2011/12 Crime Survey for England and Wales (2nd Edition). Home Office United Kingdom.

6) 2007 National Drug Strategy Household Survey. Detailed FindingS. Published by Australian Institute of Health and Welfare Canberra. 2008.

7) Report of the International Narcotics Control Board 2006. By United Nations: International Narcotics Control Board. Published by the United Nations Publication. 2006. Page 68

8) Arif A. Adverse Health consequences of cocaine abuse. World Health Organisation Geneva.1987:1-7.

9) Bock GR, Whelan J. Ciba Foundation Symposium 166. Cocaine: scientific and social dimensions. Ciba foundation 1992. Published by John Wiley and Sons limited. 2007. ISBN:9780471931799

10) M Egred, G K Davis. (2005) Cocaine and the heart. Postgrad. Med. J. 81(959):568-71

11) Jeffcoat AR Perez-Reyes M, Hill JM, Sadler NM, Cook CE. (1998) Cocaine disposition in humans after intravenous injection, nasal insufflation (snorting), or smoking. Drug Metabolism and Disposition. 17(2):153-9.

12) Inaba T. Cocaine (1989) pharmacokinetics and biotransformation in man. Can J Physiol Pharmacol. 67(9):1154-1157.

13) ]Lange RA, Hillis LD. (2001) Cardiovascular complications of cocaine use. N Engl J Med. 345:351-358.

14) Musshoff F, Lachenmeier DW, Lachenmeier K, Lachenmeier DW, Banger M, Madea B. (2006) Results of hair analyses for drugs of abuse and comparison with self-reports and urine tests. Forensic Sci Int. 156(2-3):118-123

15) Tuncel $M$, Wang $Z$, Arbique $D$, Fadel PJ, Victor RG, Vongpatanasin W. (2002) Mechanism of blood pressure-raising effect of cocaine in humans. Circulation. 105(9):1054-1059.

16) Xiao YF, Morgan JP. (1998) Cocaine blockade of the acetylcholine-activated muscarinic $\mathrm{K}+$ channel in ferret cardiac myocytes. J Pharmacol Exp Ther. 284(1):10-18

17) Gendeh B S, Ferguson B J, Johnson J T, Kapadia S. Progressive Septal and Palatal Perforation Secondary to Intranasal Cocaine Abuse. Med J Malaysia. 1998; 53(4):435-438

18) Levine SR, Burst JCM, Futrell N, Ho KL, Blake D. et al. (1990) Cerebrovascular complications of the use of the 'crack' form of alkaloidal cocaine. N Engl J Med. 323(11):699-704.

19) Brust JCM, Richter RW. (1977) Stroke associated with cocaine abuse? New York State Journal of Medicine. 77:1473-1475.

20) Noble (2006) Breaking the age bias in cocaine associated stroke. Neurology Reviews. June 14:No6.

21) Klonoff DC, Andrews BT, Obana WG. (1989) Stroke associated with cocaine use. Arch Neurol. 46(9):989-993

22) Konzen JP, Levine SR, Garcia JH. (1995) Vasospasm and thrombus formation as possible mechanisms of stroke related to alkaloidal cocaine. Stroke. 26(6):1114-1118.

23) Togna G, Tempesta E, Togna AR, Dolci N, Caprino L. (1985)Platelet responsiveness and biosynthesis of thromboxane and prostacyclin in response to in vitro cocaine treatment. Haemostasis 15(2):100-107.

24) Toler KA, Anderson B. (1988) Stroke in an intravenous drug user secondary to the lupus anticoagulant. Stroke 19(2):274-275.
25) Daras M, Tuchman AJ, Marks S. (1991) Central nervous system infarction related to cocaine abuse. 22(10):1320-1325.

26) Petty GW, Brust JC, Tatemichi TK, Barr ML. (1990) Embolic stroke after smoking "crack" cocaine. Stroke. 21(11):1632-1635

27) Morcos NC, Fairhurst AS, Henry WL. (1993) Direct myocardial effects of cocaine. Cardiovascular Research 27(2): 269-273.

28) Mody CK, Miller BL, McIntyre HB, Cobb SK, Goldberg MA. (1988) Neurologic complications of cocaine abuse. Neurology 38(8):1189-1193.

29) Smith HWB III, Liberman HA, Brody SL, Battey LL, Donohue BC, Morris DC. (1987) Acute myocardial infarction temporally related to cocaine use. Ann Intern Med. 107(1):13-18

30) Isner JM, Estes NAM III, Thompson PD, Constonzo-Nordin MR, Subramanian R, Miller G, et al. (1986) Acute cardiac events temporally related to cocaine. N Engl J Med. 315(23):1438-1443

31) Fredericks RK, Lefkowitz DS, Challa VR, Troost BT. (1991) Cerebral vasculitis associated with cocaine abuse. Stroke. 22(11):1437-1439.

32) Krendel DA, Ditter S, Frankel MR, Ross WK. (1990) Biopsyproven cerebral vasculitis associated with cocaine abuse. Neurology. 40(7):1092-1094

33) Kaye BR, Fainstat M. (1987) Cerebral vasculitis associated with cocaine abuse. JAMA. 258(15):2104-2106.

34) Morrow PL, McQuillen JB. (1993) cerebral vasculitis associated with cocaine abuse. J Forensic Sci. 38(3):732-738

35) Konzen JP, Levine SR, Garcia JH. (1995) Vasospasm and thrombus formation as possible mechanisms of stroke related to alkaloidal cocaine.Stroke. 26(6):1114-1118.

36) Kaufman MJ, Levin JM, Ross MH, Lange N, Rose SL. et al. (1998) Cocaine induced cerebral vasoconstriction detected in humans with magnetic resonance angiography. JAMA. 279(5):376-380.

37) Volkow ND, Mullani N, Gould KL, Adler S, Krajevski K. (1988) Cerebral blood flow in chronic cocaine users: a study with positron emission tomography. Br J Psychiatry. 152:641-648.

38) Nanda, Anil M.D, Vannemreddy, Prasad S. S. V. M.D, Polin, Richard S. M.D, Willis, Brian K. M.D. et al. (2000) Intracranial Aneurysms and Cocaine Abuse: Analysis of Prognostic Indicators. Neurosurgery. 46(5):1063-1069.

39) Sheryl Martin-Schild, Karen C. Albright, Hen Hallevi, Andrew D. (2010) Barreto, Maria Philip, Vivek Misra, James C. Grotta, Sean I. Savitz. Intracerebral Hemorrhage in Cocaine Users. Stroke. 41(4): 680-684

40) Pereira J, Sáez CG, Pallavicini J, Panes O, Pereira-Flores K, Mezzano D. (2011) Platelet activation in chronic cocaine users: effect of short term abstinence. Platelets. 22(8):596-601.

41) Hacke W, Kaste M, Fieschi C, Toni D, Lesaffre E. et al. (1995) Intravenous thrombolysis with recombinant tissue plasminogen activator for acute hemispheric stroke. The European Cooperative Acute Stroke Study (ECASS). JAMA. 274(13):1017-1025.

42) The International Stroke Trial (IST): a randomised trial of aspirin, subcutaneous heparin, both, or neither among 19435 patients with acute ischaemic stroke. International Stroke Trial Collaborative Group. Lancet. 1997;349(9065):1569-1581.

43) Martin-Schild S, Albright KC; Misra V, Philip M, Barreto AD. et al. (2009) Intravenous tissue plasminogen activator in patients with cocaine-associated acute ischemic stroke. Stroke. 40(11):3635-3637

44) Alberts MJ, Hademenos G, Latchaw RE,Jagoda A, Marler JR. et al. (2000) Recommendations for the establishment of primary stroke centers. Brain Attack Coalition. JAMA. 283(23):31023109.

45) Mehta SV, Gluncic V, Iqbal SM, Frank J, Ansari SA. (2012) Role of Perfusion Imaging in Differentiating Multifocal Vasospasmrelated Ischemia versus Thromboembolic Stroke in a Setting of Cocaine Abuse. J Stroke Cerebrovasc Dis. 21(8):904. 
46) Qi Fu Huang, Asefa Gebrewold, Bella T. (1990) Altura, Burton M. Altura. Cocaine-induced cerebral vascular damage can be ameliorated by $\mathrm{Mg}^{2+}$ in rat brain. Neuroscience Letters. 109 (12): $113-116$

47) Muir KW, Lees KR, Ford I, Davis S. (2004) Intravenous Magnesium Efficacy in Stroke (IMAGES) Study Investigators. Magnesium for acute stroke (Intravenous Magnesium Efficacy in Stroke trial): Randomised controlled trial. Lancet, 363 (9407):439-445.
48) https://assets.publishing.service.gov.uk/government/uploads/syst em/uploads/attachment_data/file/461334/Cocaine_report_min_r esponse.pdf 
